\title{
Features of the working process of high-speed diesel engines
}

\author{
Sarvar Kadirov ${ }^{1 *}$, Madamin Aripdjanov ${ }^{2}$, Obidjon Ergashev ${ }^{1}$, and Ravshan Iskandarov ${ }^{1}$ \\ ${ }^{1}$ Tashkent State Transport University, Tashkent, Uzbekistan, \\ ${ }^{2}$ Ministry of Higher and Secondary specialized education of the Republic of Uzbekistan, Tashkent, \\ Uzbekistan,
}

\begin{abstract}
This article discusses the main history of the creation of highspeed short-stroke diesel engines and an assessment of the main factors that most significantly affect the working process of a diesel engine. When developing a new design of a high-speed diesel engine, it is necessary to pay special attention to the following factors: the intensity of the air charge, injection pressure parameters, the shape of the combustion chamber and the choice of the best option. Research carried out with a $7 \mathrm{x}$ $0.15 \mathrm{~mm}$ nozzle in a wide range of speed changes $(n=1000+2800 \mathrm{~min}-1)$ shows that it is possible to find a position of the widened valve at which optimal results are obtained at medium and high rotational speeds, and on small - engine performance will deteriorate slightly.
\end{abstract}

\section{Introduction}

The famous scientist in the field of engine building N.R. Briling with his students-designers at the OKB (Special Design Bureau) at plant No. 40 of the USSR Ministry of Automotive Industry in 1954 created the DB-67 diesel engine (naturally aspirated $\mathrm{Ne}-180 \mathrm{hp}$ at 3000 $\min ^{1}-$ ) [1].

At the end of the 50s, the USA developed a new high-speed short-stroke diesel Cummins based on the scientific results obtained by N.R.Briling and received an international patent. And the patent experts of the USSR at one time refused to NR Briling. What injustice?! Currently, the US Army is mainly equipped with these diesels. They only installed their own unit injector.

The basic issues that arise when solving the problem of increasing the diesel engine speed, along with obtaining a reliable and durable design, are the provision of high-quality fuel injection during a small crank angle, the complexity of organizing high-quality mixture formation and complete combustion, as well as ensuring the necessary cylinder cleaning and high filling. These problems are associated with the organization of the diesel engine workflow.

A characteristic feature of these diesel engines is a low ratio $\mathrm{S} / \mathrm{D}=0.75-0.80$, which, along with other positive properties, makes it possible to place 4 valves per cylinder with individual inlet and outlet pipes, thus ensuring an increase in the filling ratio. The injection is carried out using a pump injector. The pump-injector plunger also functions as a shut-off

*Correspondingauthor:skodirov@mail.ru 
needle of the atomizer, for which the elasticity of the pump-injector drive elements is used. Combustion chamber: unseparated - single-cavity formed by a recess in the piston (Gesselman type); fuel is supplied using an atomizer with 7 nozzle holes. The air in the combustion chamber receives a directed vortex rotation using the visors at the intake valve seats.

Despite the great success in creating high-speed, highly efficient automobile direct injection diesel engines, many important issues related to the choice of fuel supply equipment, vortex formation in the cylinder, characteristics of fuel supply to the cylinder, and further forcing in terms of speed remain unresolved.

These circumstances are a sufficient basis for further research on the methods of organizing the working process of high-speed diesel engines.

\section{Materials and methods}

Single Cylinder Diesel Unit: The above considerations were used as the basis for developing the design of a single-cylinder diesel unit (ODU) to study the working process of a diesel engine of a promising car.

Diesel has the dimension $\mathrm{D}_{\mathrm{c}}=115 \mathrm{~mm}$ and the piston stroke $\mathrm{S}=96 \mathrm{~mm}$, which gives the ratio $S / D=0.83$. The working volume of one cylinder is $V_{h}=1 L$. At the specified nominal speed $\left(\mathrm{n}=2800 \mathrm{~min}^{-1}\right)$, it is possible, in the case of a good organization of the working process, to achieve high power $\mathrm{N}_{\mathrm{e}}=25 \mathrm{hp}$ during the operation of a diesel engine without supercharging.

Currently, this high-speed diesel engine at the Tashkent Automobile and Road Institute is equipped with a Hydrogen Generator, and optimization studies of the working process are underway.

The noticeable increase in the limiting values of the average effective pressure $\mathrm{Pe}$ in single-cavity combustion chambers achieved in recent years is largely the result of the development of effective measures for the use of directed air movement during the intake process.

The use of widened valves $(\mathrm{ZK})$ is advisable when:

1. Study of the influence of the movement of the air charge on the process of mixture formation and combustion. Changing the intensity of the vortex using the gearbox is possible over a wide range without stopping the engine.

2. The need to change the intensity of the vortex following the needs of the operation.

$\mathrm{ZK}$ is effective in the case of engines with 4 valve heads per cylinder. The development of tangential and, moreover, screw channels in such engines is structurally difficult to carry out. The use of ZK reduces the requirements for the accuracy of the die casting.

In wide single-cavity combustion chambers, the main attention is paid to the axial vortex since the radial displacement flow during compression does not create a sufficient air velocity due to the large $d_{c} / D_{c}$ ratio. It is believed [4] that an already moderate speed of $4.5+6 \mathrm{~m} / \mathrm{s}$ improves fuel distribution in the chamber. At speeds up to $18 \mathrm{~m} / \mathrm{s}$, air only destroys the jet shell and contributes to all fuel distribution through the combustion chamber.

Determined that:

a) The air speed in the cylinder is directly related to the speed of the engine;

b) There is a certain relationship between the nature of the movement of the air charge during the processes of intake and compression;

c) Widening of the intake valve contributes to the creation of a rotational air flow in the diesel cylinder. 


\section{Results and Discussion}

Experimental determination of the air charge speed: In this work, the problem is posed by measuring the movement of the air charge in different zones of the combustion chamber to obtain quantitative data on the speed of movement of the air charge in a wide range of changes in the rotation frequency $\left(\mathrm{n}=1000-2800 \mathrm{~min}^{-1}\right)$. The measurements according to the developed technique were carried out using an ETA-5A electric hot-wire anemometer.

In this case, it is possible to measure the speed of air movement in different chamber zones, located perpendicular to the connecting axis of the valves of the same name.

To determine the speed of the air charge, it is necessary to have an oscillogram of the pressures in the engine cylinder and changes in the current of the measuring bridge over the angle of rotation of the crankshaft during the intake-compression process.

According to the calibration data of ETA-5A sensors, the velocity components were determined - radial, tangential, along the cylinder axis, and as a result, the velocity vector.

Measurements are made on scrolling at water and oil temperatures corresponding to their values during operation under load. During testing, the sensor is mixed in the center plane along the bulkhead separating the valves of the same name. Measurements are made at 5-6 points along the radius of the combustion chamber at a speed of 1000 to $2800 \mathrm{~min}^{-1}$, at different rates of air charge movement, determined by the angle of installation of the widened valve. The measurements were taken after 300 turns of the screen. In our studies, the measuring thread of the sensor was located along the radius of the chamber, which ensures the registration of mainly tangential and vertical components of the air velocity. In fig. 1, as an example, an oscillogram is shown taken while measuring the air charge velocity in the combustion chamber area $\left(r_{k}=43 \mathrm{~mm}\right)$ at $n=1000$ and 2800 min-1, taken with three positions of the screen on the valve $\left(\varphi_{\mathrm{sh}}=90^{\circ}, \varphi_{\mathrm{sh}}=150^{\circ}\right.$ and $\left.\varphi_{\mathrm{sh}}=270^{\circ}\right)$. It can be seen that as the screen rotates in a position at which the flows entering the cylinder through both valves meet to a greater extent, the velocity pulsation increases, which is especially detected when the piston is positioned near the TDM.
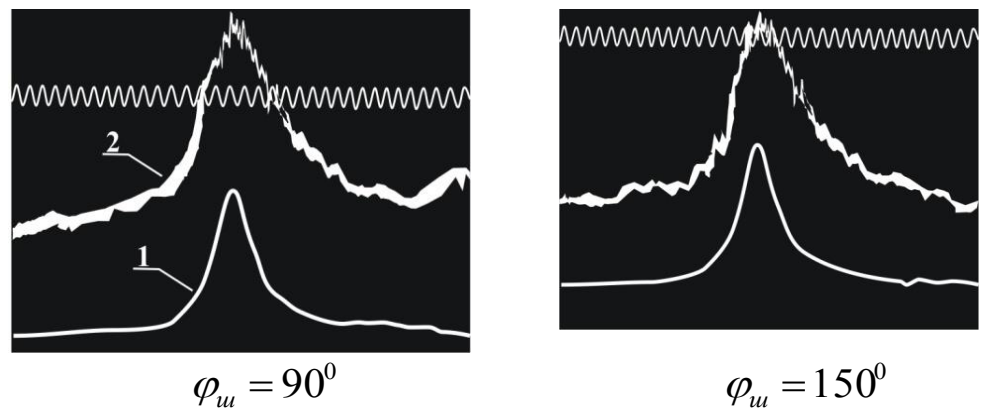

$$
\varphi_{u}=90^{0}
$$$$
\varphi_{u}=150^{0}
$$

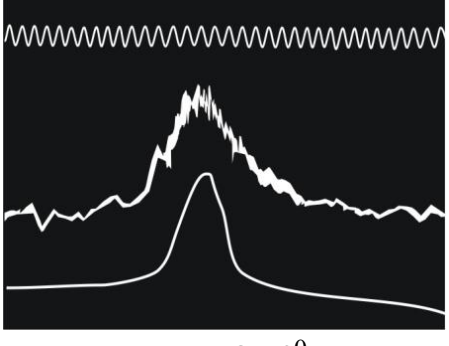

$$
\varphi_{u}=270^{0}
$$

Fig. 1. Samples of oscillograms obtained at different angles of installation of the screen: 1 is pressure in the cylinder; 2 is air velocity pulsation. 
In figure 2 shows the values of the air speed by the angle of rotation of the crankshaft for 3 positions of the screen. It can be seen that by the end of the compression stroke, the intensity of the vortex increases the more, the closer the position of the screen on the valve, providing the maximum of the vortex.

$$
\mathrm{n}=1000 \text { мин }^{-1} ; \quad \mathrm{h}_{\mathrm{k}}=6 \text { мм; } \mathrm{r}_{\mathrm{k}}=43 \text { мм; }
$$

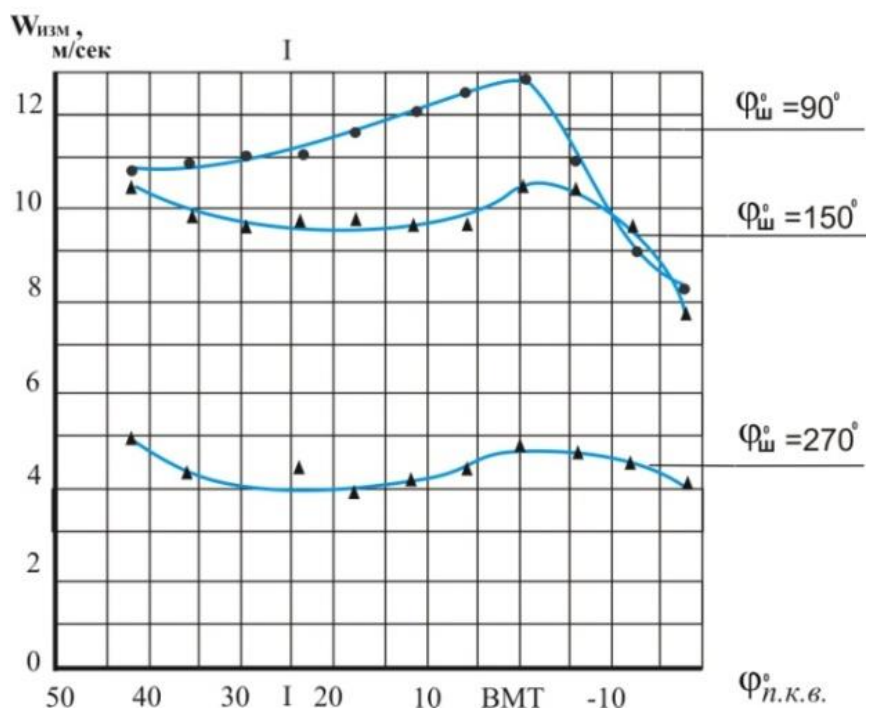

Fig. 2. Air charge velocity as a function of the crankshaft rotation angle at different screen installation angles

Consideration of the data obtained makes it possible to establish that the dependence of the air charge velocity on the angle of rotation of the widened valve is common for all investigated zones of the combustion chamber and rotation frequency, as well as the depth of measurements. The maximum speed is achieved at $\varphi_{\mathrm{sh}}=90^{\circ}$. The Wmeas value at this position of the screen is the greater the further the sensor is located from the center of the camera.

In figure 3 shows the values of air velocity in vm.t. as a function of the crankshaft speed.

The obtained research results (see Figure 3) suggest that when the screens are positioned at which a counter-movement of the air charge through both valves is formed, the tangential velocity component is almost completely damped and is approximately equal in value to the average piston speed. 


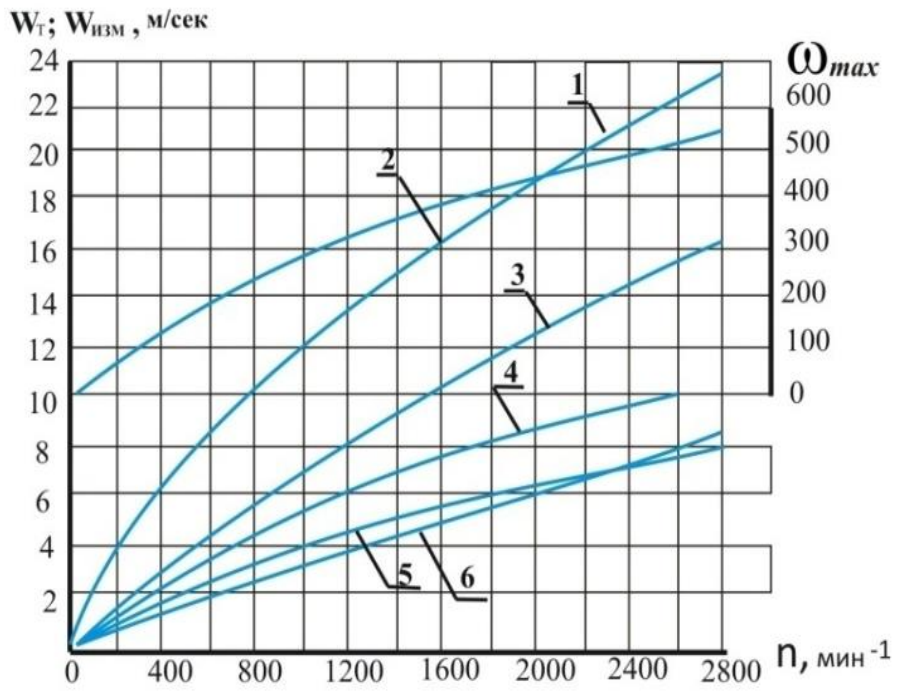

Fig. 3. The speed of movement of the air charge in the VMT as a function of crankshaft speed

Applying this assumption, we can determine the tangential component of the velocity from the equality

$$
\mathrm{W}_{\mathrm{T}}=\sqrt{\mathrm{W}_{i z m}^{2}-C_{\Pi}}, \quad \mathrm{m} / \mathrm{sec}
$$

Where: $\mathrm{W}_{\mathrm{izm}}$ is measured with the help of ETA speed value, in $\mathrm{m} / \mathrm{s}$;

$\mathrm{C}_{\mathrm{n}}=\mathrm{W}_{6}$ is the average piston speed is approximately equal to the value of the vertical component of air movement, in $\mathrm{m} / \mathrm{s}$,

It should be noted that a different combination of the positions of the two screens affects the speed pulsation.

Influence of the intensity of movement of the air charge and the parameters of the fuel supply equipment on the performance of the engine and the dynamics of heat release.

In figure 4 shows the injection pressure diagrams at 2 calibers for $n=1000$ and 2800 $\min -1$ at $\mathrm{q}_{\mathrm{c}}=50 \mathrm{mg} /$ cycle. It can be seen that in the zone of maximum injection pressures, the use of a caliber $\mathrm{K}=37.4 \mathrm{~mm}$, at which in this injection section, the speed of the plunger movement along the TKGP is $40 \%$ higher compared to $\mathrm{K}=39.3 \mathrm{~mm}$, the injection pressure is about $12.5 \%$ higher. The working section of the fuel cam profile on the injection rates when the engine is equipped with a pump-injector was also noted in [2, 4]. Considering the results obtained, it was considered expedient to carry out experiments to study the effect of the intensity of the air vortex on the processes of mixture formation and combustion using two setting calibers. 


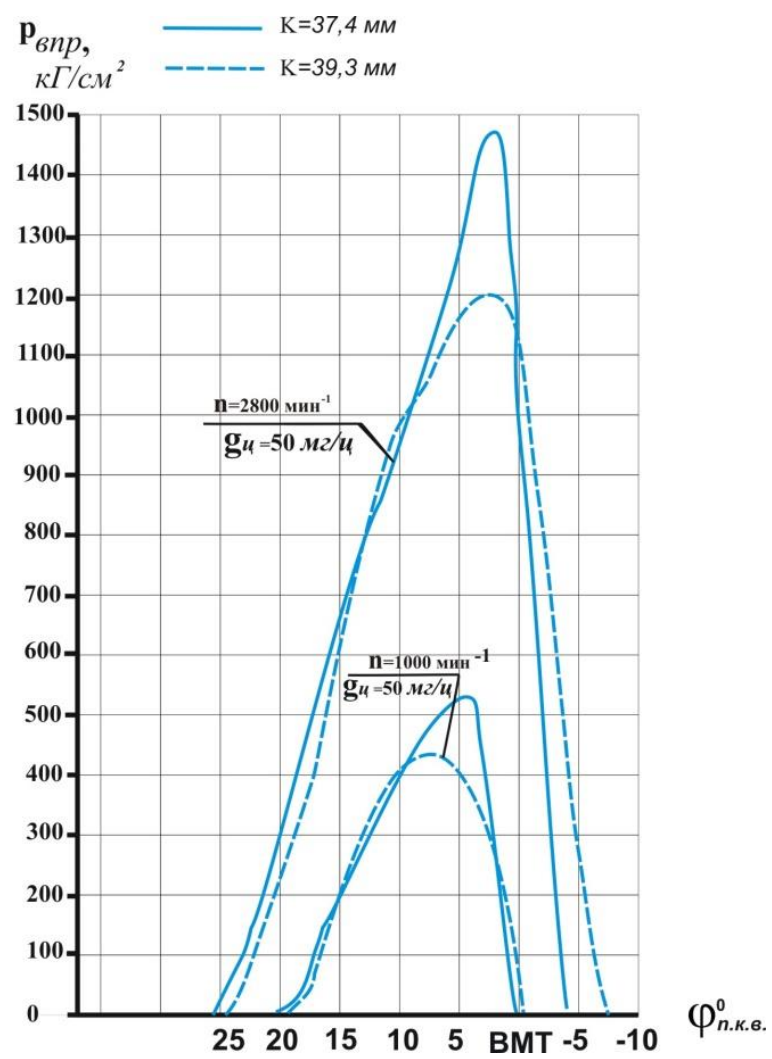

Fig. 4. Diagram of fuel injection pressures (cam №1).

Figure 5 shows the dependence of the specific fuel consumption, average indicator pressure, opacity and temperature of exhaust gases at 2 calibers on the change in the position of one of the widened valves with a fixed position of the second, providing the maximum vortex.

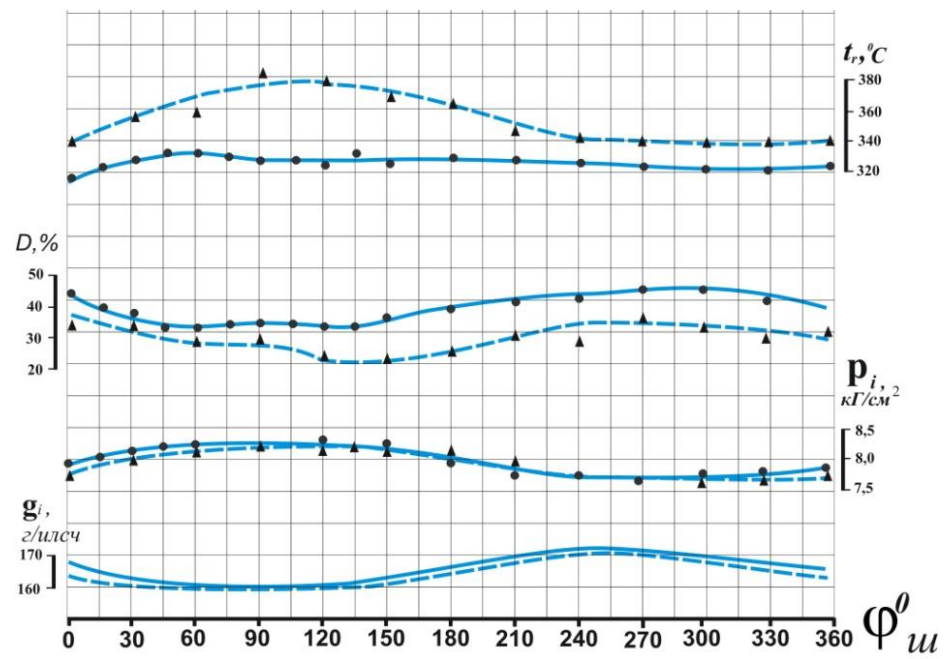

Fig. 5. Adjustment characteristics for the angle of rotation of the rotated recessed valve 
Figure 6 shows the experimental data of a diesel engine at different calibers, angles of rotation of the widened valves, i.e. vortex velocity and at different speeds of rotation in the angle of rotation of the crankshaft.
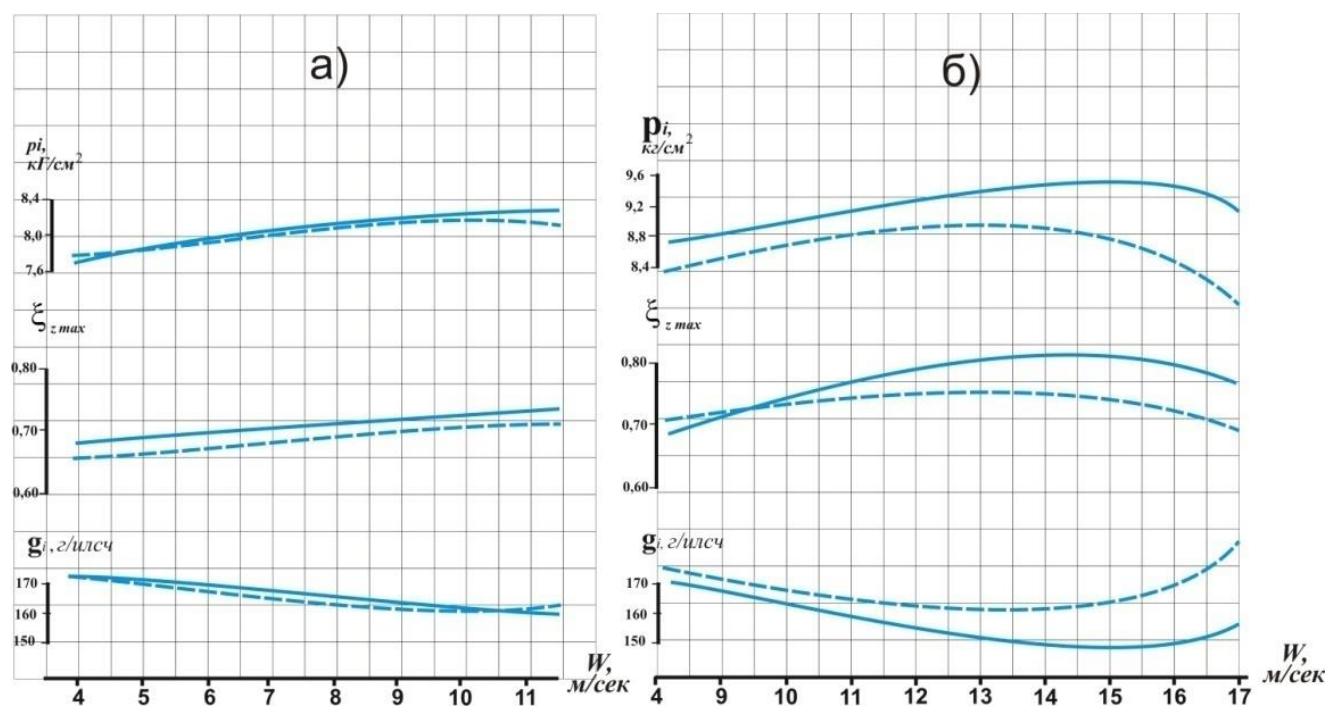

Fig. 6. Indicators of the engine as a function of the absolute speed of the air charge: a) $n=1000$ min${ }^{1}$; b) $\mathrm{n}=2800 \mathrm{~min}^{-1}$

$$
K=37.4 \mathrm{~mm} ; K=39,3 \mathrm{~mm}
$$

In figure 7 shows the adjusting characteristics for the angle of rotation of the rotated reamed valve at different cycle feeds: a) $n=1000$ min $^{-1}$; b) $n=2800 \mathrm{~min}^{-1}$; $\mathrm{K}=37.4 \mathrm{~mm} ; \mathrm{K}=39.3$ $\mathrm{mm}$

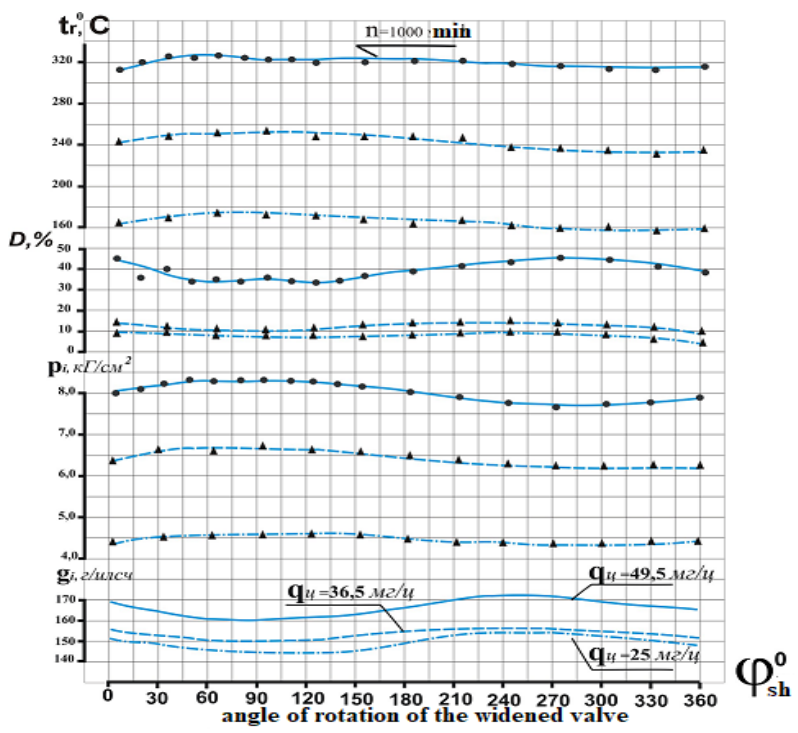

a) 


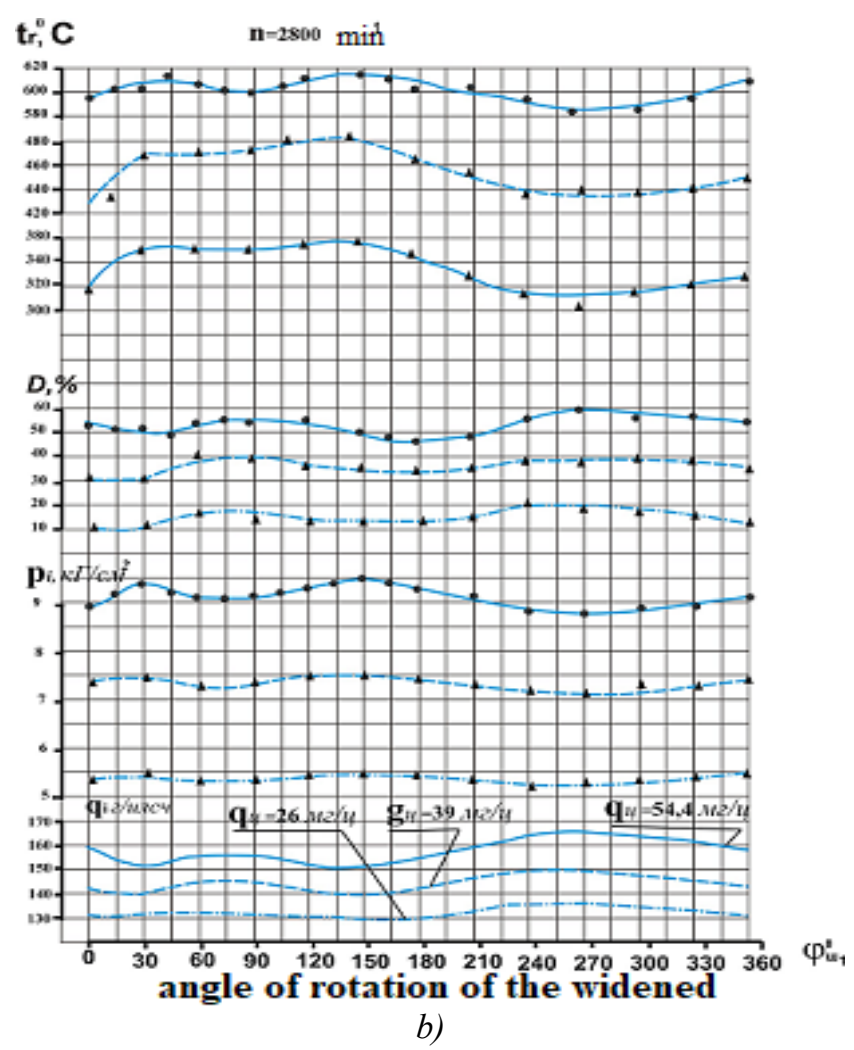

Fig. 7. Adjustment characteristics for the angle of rotation of the rotated, widened valve at different cycle feeds: a) $n=1000 \min ^{-1}$; b) $n=2800$ min $^{-1}$.

Figure 8 shows the adjusting characteristics for the angle of rotation of the widened valve at different speeds.

In figure 9 shows the characteristics of heat release at different speed conditions. It can be seen that the highest rate of increase in $\mathrm{pz}$ in the fast combustion phase takes place at $\mathrm{n}=$ $1000 \mathrm{~min}^{-1}$. At the same time, the maximum value for this high-speed made is significantly less than for all other modes. The angle of rotation of the crankshaft corresponding

$\varphi_{\xi_{\max }}, \varphi_{T_{\max }}$ and $\varphi_{p_{z}}$ with an increase in rotation frequency 


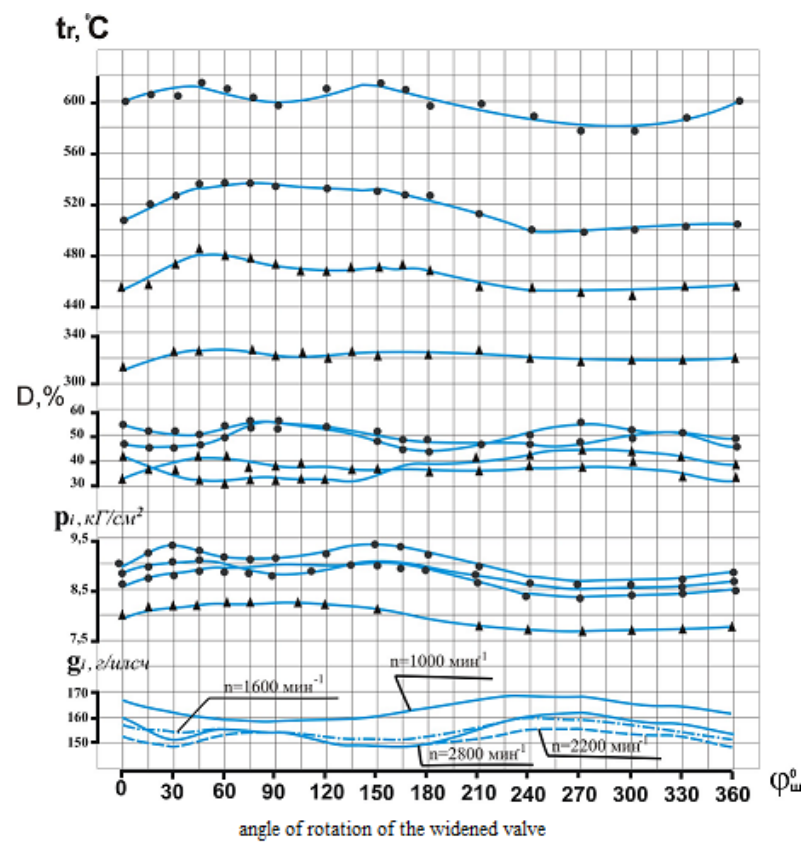

Fig. 8. Adjustment characteristics for the angle of rotation of the widened valve at different speeds at $\mathrm{Q}_{\mathrm{c}}=$ const $=50 \mathrm{mg} / \mathrm{c}$.

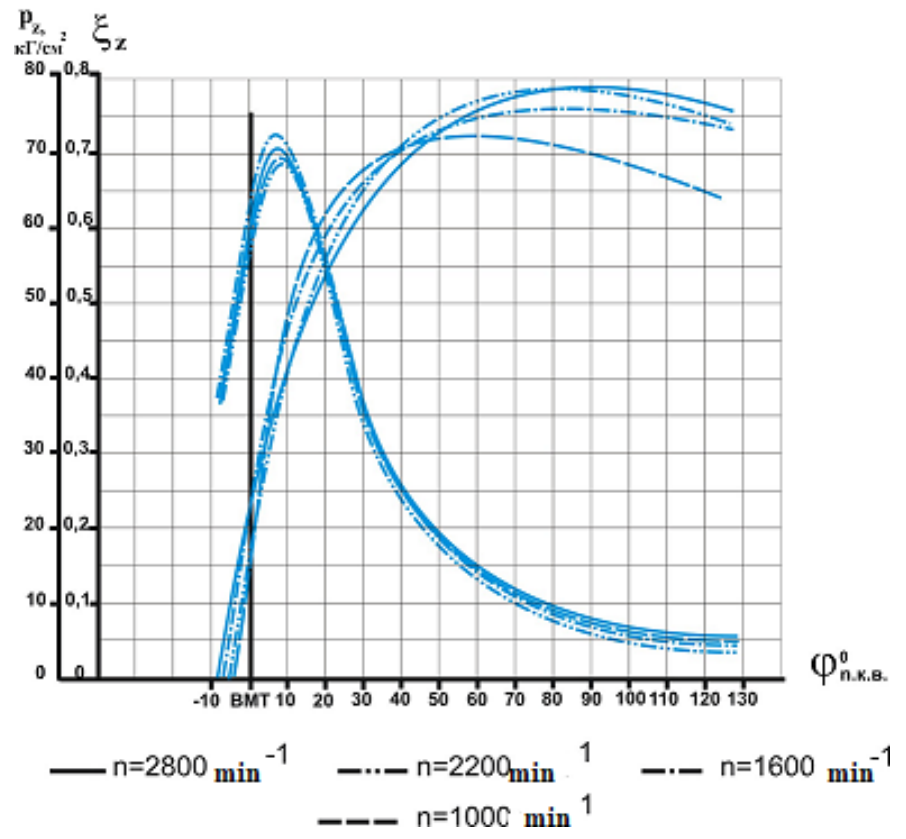

Fig. 9. Pressure in the cylinder and characteristics of active heat generation as a function of the angle of rotation of the crankshaft at different speeds

In figure 10, a) and b) shows the data of processing indicator diagrams on the characteristic of heat release for all investigated speed modes at optimal, maximum and minimum vortex intensity at the position of the widened valve $\varphi_{u}=90,150$, and 270 , respectively. 

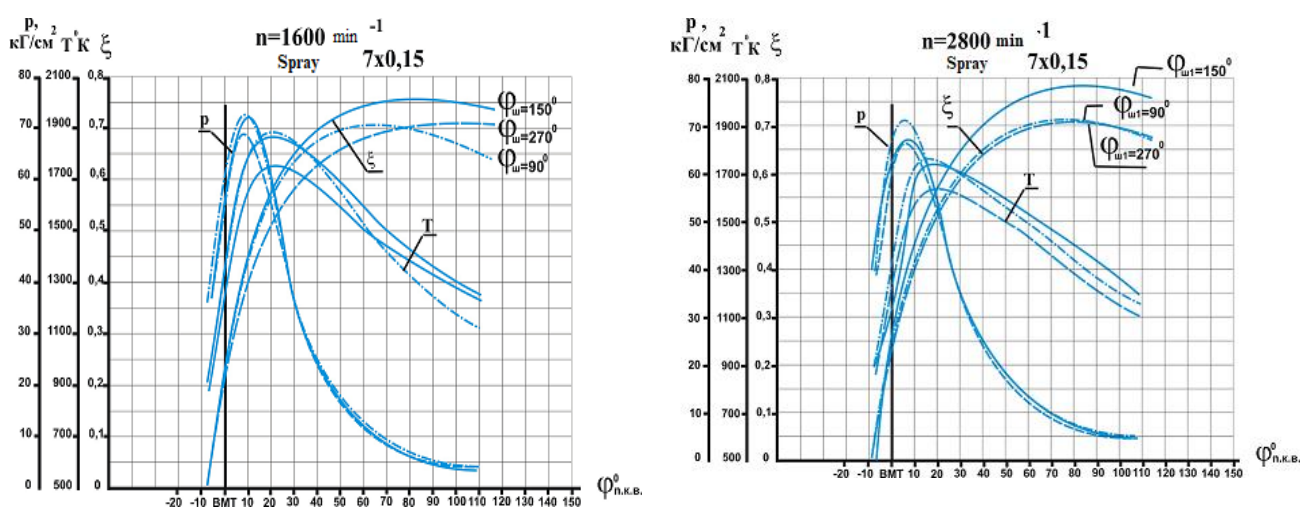

Fig. 10. Indicators $\mathrm{p}, \mathrm{T}$ and $\xi$ various angles of installation of the widened valve from the angle of rotation of the crankshaft

It can be seen that for all investigated speed modes, the optimal engine performance corresponds to the highest value ( $\xi_{\max }$ ).

\section{Conclusions}

Analysis of the data obtained allows us to draw the following conclusions:

1. Changes in the intensity of movement of the air charge in a single-cavity combustion chamber of a diesel engine within the investigated limits significantly affect the economic and power indicators as well as the characteristics of heat release and the value of the coefficient of active heat release.

2. With an increase in the speed of the organized movement of the air charge in the combustion chamber, an acceleration of the combustion process is observed in the initial stage; the maximum heat release is reached earlier (when the optimum in air speed is reached, for example, $\left(\mathrm{n}=1000 \mathrm{~min}^{-1}\right)$, the ignition delay period is somewhat reduced, and more noticeable at low speeds, in conditions of deteriorating spraying.

3. Research carried out with a $7 \times 0.15$ nozzle in a wide range of speed changes $(n=1000$ +2800 min- $^{-1}$ ) shows that it is possible to find a position of the widened valve at which optimal results are obtained at medium and high speeds and small - engine performance will deteriorate slightly. This corresponds to the reduced vortex velocity at $\operatorname{TDC}\left(\mathrm{n}_{\mathrm{e}} / \mathrm{n}_{\mathrm{dv}}\right)=1.60\left(\varphi_{u}=150^{\circ}\right)$.

4. The working section of the profile of the fuel cam of the pump-injector, characterized by the "gauge", has little effect on the formation of optimal conditions for mixture formation. However, it somewhat affects the engine's performance.

5. To obtain optimal engine performance at a cycle rate close to the nominal, it is necessary that the air vortex rotates approximately by an angle between two adjacent flares during the injection duration.

\section{References}

1. V.F.Vodeiko, A.S. Khachiyan. Special Design Bureau of Professor N.R.Briling. Moscow, MADI..(2017) -p. 43.

2. S.M. Kadyrov, S.E. Nikitin, A.L. Karunin. Automotive and tractor engines. Moscow. Ed. the science, $-(2007)$, p. 32 
3. S. Kadirov, N. Paswan. INTERNAL COMBUSTION ENGINES. New Dehli. India. (2013). - p. 32.

4. S. Kadirov. Investigation of the working process of a short-stroke diesel engine with a single-cavity combustion chamber (Series of lectures) Tashkent: TashPI, (1974) -pp. 1.5

5. Keramische hochleistungsbauteile für den Motoren und Triebwerksbau // VDI/BadenBaden, 1985.

6. Les motours et la ceramique // Poids Lourds. 1984. № 828. P. 18-21.

7. Thelliez M. Nouvelle description parametrique de la loide degagement de chaleur des mateurs diesel a injection directe. / Entropie. 1982. Vol. 18. № 105. P. 17-21.

8. Engine material innovations from Japan // Diesel Progress North American. 1985. Vol. 51. №5. P. 14-16.

9. Kamo R. High technology ceramics for Japanese heat engines // Materials Research Society. 1984. Vol. 8. № 2. P. 415-440.

10. Martin E., Hayter A.J. Modern Trends in Diesel Enqine Coolinq // The Oil Engine. 1953. № 2.

11. Kamo R., Bryzik W. Cummins-TARADCOM adiabatic turbocompound engine program // SAE Technical Paper Series. 1981. № 810070. P. 10-15.

12. Shimauchi T., Murakami T., Nakagaki T. et al. Tribology at high tempera-ture for uncooled heat insulated engine / SAE Technical Paper Series. 1984. № 840429. P. 3545.

13. Pierpont D.A., Montgomery D.T., Reitz R.D. Reducing Particulate and NOX Using Multiple Injections and EGR in a D.I. Diesel // SAE Technical Paper Series. 1995. № 950217. P. 1-10.

14. Takemoto Y. et al. Improvement of thermal efficiency and reliability of four-stroke medium speed diesel engines // 15th International Congress on Combustion Engines, Paris, France, June 1983. P. 949-975.

15. Long Z., Ueda T., Takatsuki T., Yokota K. The Study of the Effects of Chamber Geometry on Flame Behavior in a DI Diesel Engine // JSAE Re-view. 1995. Vol. 16. Issue 3. P. 320-321.

16. Watson N., Kyrbatos N.P., Holmes K. The performance potential of limited cooled diesel engines // Proceedings of the Institution of Mechanical Engi-neers. 1983. Vol. 197. P. 197-207.

17. Yashimitsu T., Tojoma K., Sato F., Yamaguchi H. Capabilities of heat insu-lated diesel engine // SAE Technical Paper Series. 1982. № 820431. P. 1-19.

18. Godfrey D.I., Parker D.A., Rhodes M.L., Smart R.F. Research on the use of ceramics in diesels // «Ceram: High Performance». Apple. 3: Reliab. Proc. 6 th. Arme Mater. Technol. Conf., Orcas. Island. Wash., 10-13 July 1979. New-York - London. 1983. P. 81-99.

19. Woschni G., Spindler W., Kolesa K. Heat insulation of combustion cham-ber walls a measure to decrease the fuel consumption of JC engines? // SAE Technical Paper Series. 1987. № 870339. P. 1-11.

20. Popovać M., Hanjalić K. Compound Wall Treatment for RANS Computa-tion of Complex Turbulent Flow // Proc. 3rd M.I.T. Conference. Boston (USA), 2005. P. 128.

21. Elsbett L. Entwicklung eines Dieselmotors mit wärmedichterer Verbrennungsraum // MTZ. 1981. Jg. 42. № 3. P. 99-105. 